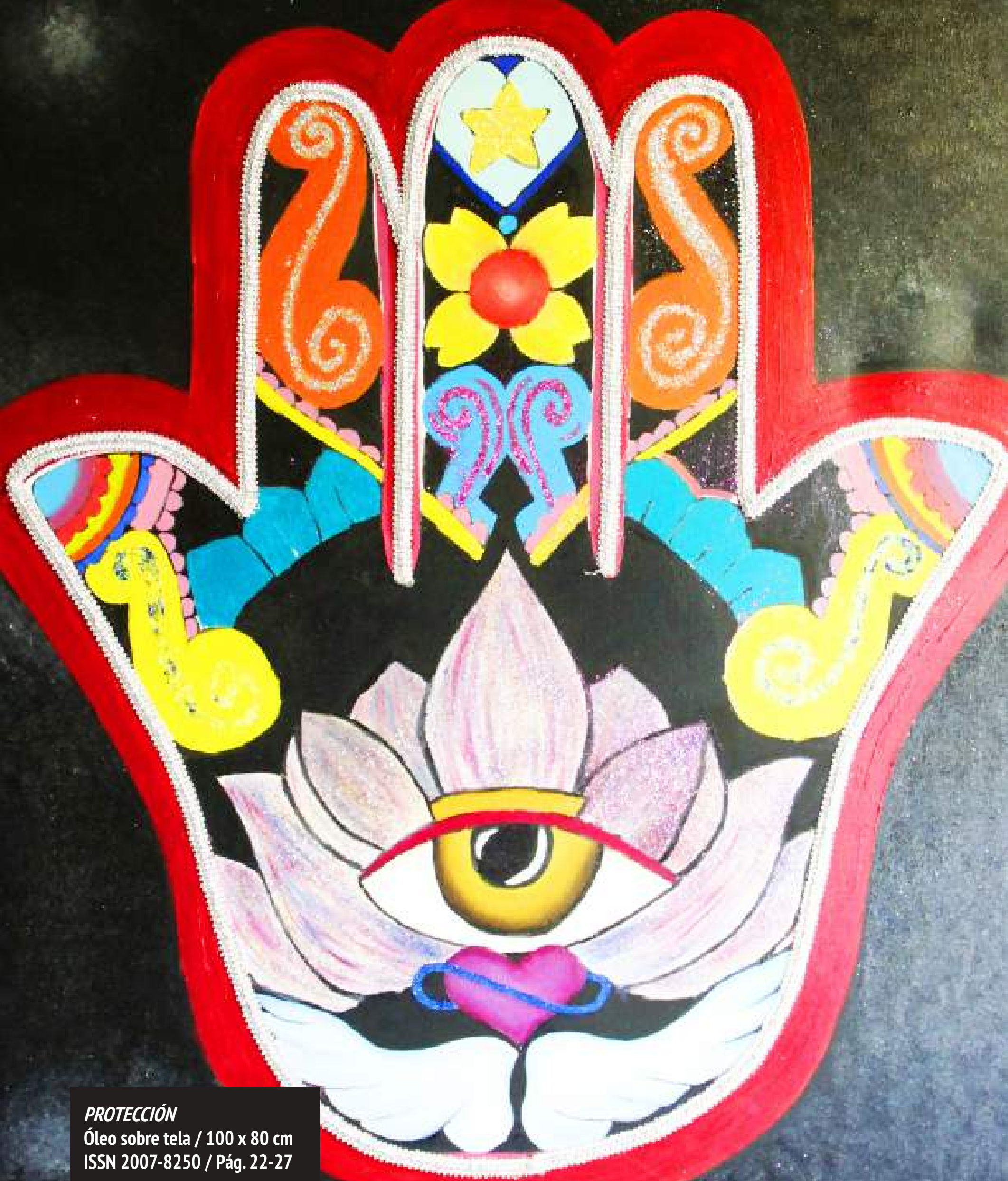




\section{LA ENSEÑANZA DE LA LITERATURA A LOS ADOLESCENTES}

Rosaura Barahona

No. 4 - Mayo 1991

$T$ os jóvenes no saben leer ni escribir es quizá la queja que hermana a todos los maestros de bachillerato alrededor del mundo. Ni los franceses ni los alemanes, que durante años tuvieron fama de manejar muy bien su propio idioma, pueden eludir el problema de la lectura y la escritura en los estudiantes de hoy. 
$\mathrm{P}$ ara quieres llevamos mucho tiempo en la enseñanza, el que una queja adquiera carácter de lugar común, es señal de alerta. Si sólo una minoría de los estudiantes adolescentes alrededor del mundo saben escribir y disfruta leyendo, ¿no estaremos planteando mal el problema? ¿No será que debemos extender la definición de lectura a algo más que el descifrar un código verbal?

A quienes fuimos educados con la palabra y por la palabra nos parece insólito y ofensivo que los alumnos no lean. No sólo creemos firmemente que serán más ignorantes que nosotros, sino que nos cuesta trabajo entender cómo el placer de la lectura puede resultarles aburrido. Es decir, el conflicto no es sólo entre maestros y estudiantes, sino entre lectores y no lectores, entre los defensores del verbo y los seguidores de la imagen y el audio. Y no es un conflicto banal.

Sabemos que la educación actual no está preparada para enfrentar a estudiantes provenientes de un mundo oral y visual, para quienes la escritura son tareas onerosas y, a menudo, inútiles.

Por ejemplo, el género epistolar que durante siglos nos ha dado acceso a la intimidad de personajes célebres, en unos cuantos años habrá desaparecido para siempre, a menos, claro, que alguien se considere tan importante que decida escribir para tener un expediente de toda su correspondencia.

La cultura actual, práctica y veloz, prefiere el teléfono. $Y$ debemos entenderlo. Hace un siglo llamar de una ciudad a otra era casi imposible. En

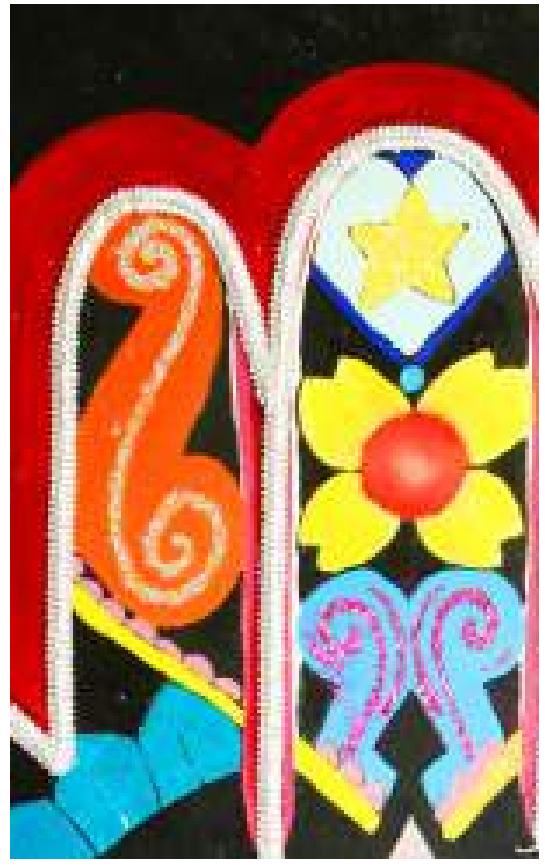

la actualidad, no cuesta más de un minuto entrar en contacto con cualquier rincón del mundo. Así ¿para qué habría de escribir un joven a su padre, a su abuela 0 a su novia si puede escuchar su voz y comunicarse de forma inmediata?

Los recados amorosos escondidos entre las páginas de un libro o en las ropas de la nana celestina, ha caído también en desuso. Las nanas ya no existen y los jóvenes no tiene ni para qué quebrarse la cabeza escribiendo algo de cuya originalidad y belleza siempre dudarán, cuando en la tienda de la esquina se vende todo tipo de tarjetas con el mensaje adecuado

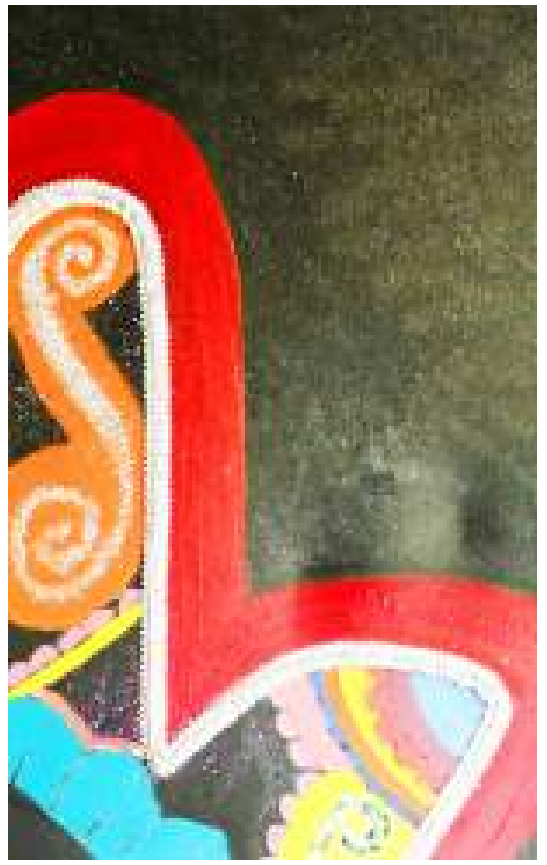

para cada ocasión. Lo impersonal 0 lo anónimo del mensaje les tiene sin cuidado. Para nosotros, escribir es conocerse. Para ellos, no: la reflexión que precede a la palabra escrita, el bucear en uno mismo para seleccionar el término o el tono adecuados, carecen de sentido.

En nuestro país, los programas de lengua y literatura a nivel de bachillerato no han podido -por alguna razón que a mi en lo personal me parece inexplicable- sacudirse la influencia decimonónica. Aunque el número de horas de clase se ha visto reducido en muchos centros de estudio para dar cabida a otros cursos,

\section{El conflicto no es sólo entre maestros y estudiantes, sino entre lectores y no lec- tores, entre los defensores del verbo y los seguidores de la imagen y el audio}


Por su índole creativa y sintética, la literatura exige tarde o temprano que el lector haga la transferencia de la ficción a la realidad cotidiana

los programas se siguen integrando de la manera tradicional: por épocas, por movimientos o por países.

Se olvida, sin embargo, que a las aulas llegan estudiantes que si bien certifican haber estudiado por lo menos nueve años, han leído sólo aquellas cosas que debieron memorizar para aprobar los exámenes. ¿Cómo podemos esperar, entonces, que se entusiasmen con "La llíada", "La Odisea"0 con Sófocles, Esquilo y Eurípides, de la noche a la mañana? Estos alumnos, lectores de revistas de chismes artísticos o de cómicos, no pueden sino espantarse con el grosor de " $E l$ Quijote"o de "Madame Bovary". Y los

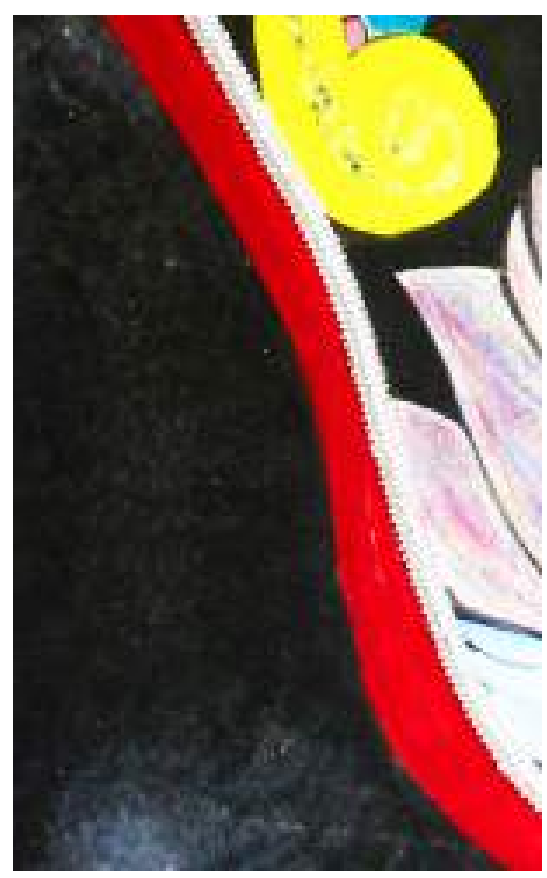

maestros deberíamos ser capaces de entenderlo.

Los defensores del libro como instrumento básico de educación, insisten en que la lectura es un proceso mental ordenado. Nos exige sentarnos, aislarnos (al menos mentalmente) a el tiempo que dure la lectura, descifrar un código de izquierda a derecha, entender los conceptos contenidos en el mensaje y emitir juicios - no necesariamente exteriorizarlos- sobre la verdad o la falsedad de tales conceptos. Por su índole creativa y sintética, la literatura exige tarde 0 temprano que el lector haga la transferencia de la ficción a la realidad

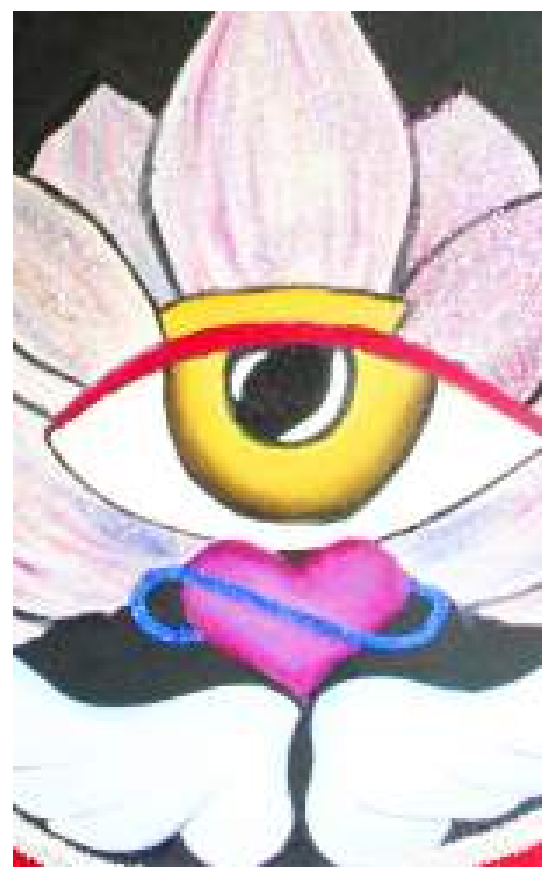

cotidiana. Entender lo simbólico, lo mítico, lo arquetípico le dará armas para hacer una disección en su realidad y tratar de conocerla o entenderla mejor.

Si un lector se queda en primer nivel de lectura, es decir, en lo concreto, su aprendizaje será mucho más limitado que el de aquél capaz de atraer las ideas del autor. El primero memorizará y repetirá; el segundo, deberá interpretarla, lo que le exige el replanteamiento de los puntos claves de su propia cosmovisión.

Por lo contrario, y de acuerdo con Neil Postman, catedrático de comunicación de la Universidad de Nueva York, la televisión es por naturaleza disconexa y fragmentada. Funciona en contra de la tradición lineal del pensamiento lógico. En la televisión, la emoción más intensa de una historia se interrumpe súbitamente para dar lugar a otro espacio, a otro "personaje" y a otra mini-historia que nada tiene que ver con la interrumpida. Así, por ejemplo, el momento

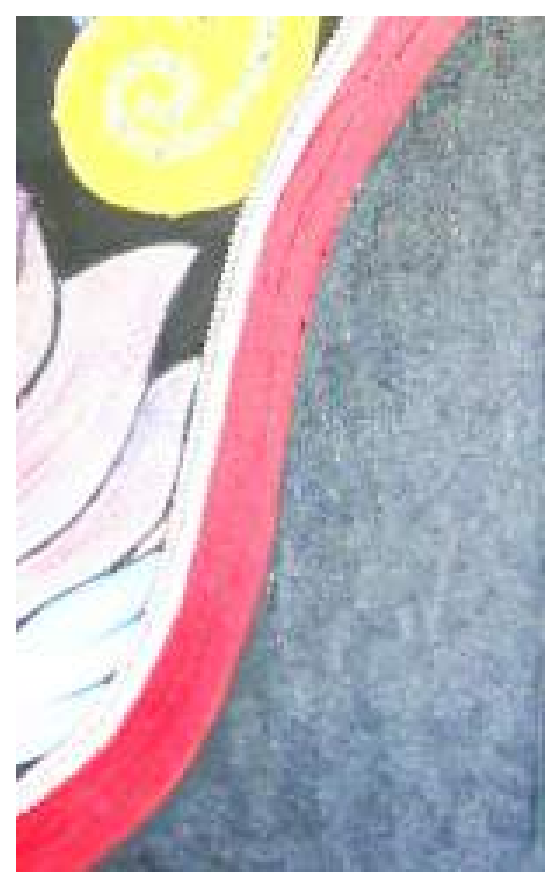


climático en el que la heroína va a ser asesinada, se suspende para que los espectadores puedan ver la efectividad de un detergente, de un dentífrico o de un automóvil. El suspenso es retomado minutos después y la historia continúa.

Para quienes fuimos formados en la lectura, estos elementos son distractores y significan una ruptura herética de la narración. Sin embargo, -y esto ocasiona problemas a muchos adultos- quienes han crecido frente al televisor, no tienen ninguna dificultad para retomar la historia. De hecho, muchos saben de antemano en donde vendrá un corte comercial y lo aprovechan para realizar otro tipo de actividades.

Lo anterior podría estar relacionado con un fenómeno que se dio entre la generación que vio surgir la televisión y la que creció frente a ella. Los primeros tuvieron que estudiar en qué consistía el lenguaje cinematográfico o televisivo. Los jóvenes lo asimilaron sin necesidad de estudiar-

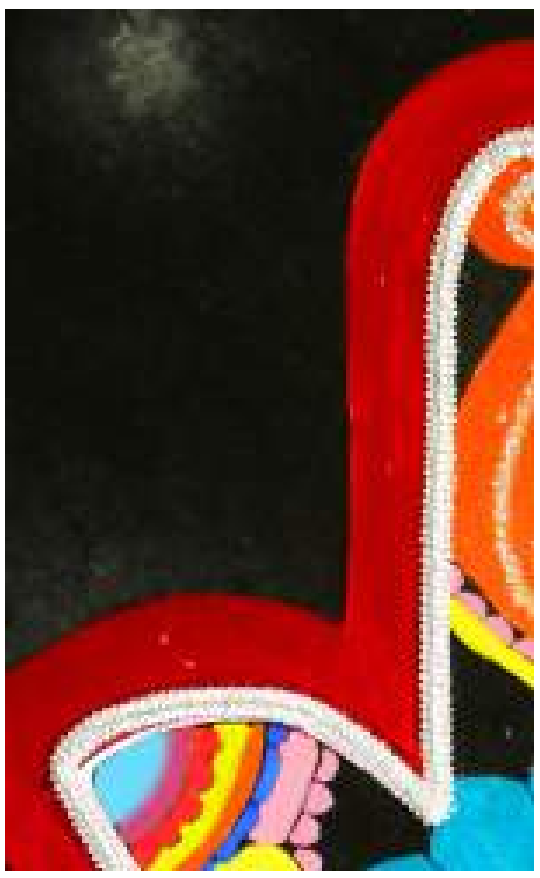

Los primeros tuvieron que estudiar en qué consistía el lenguaje cinematográfico o televisivo. Los jóvenes lo asimilaron sin necesidad de estudiarlo

lo, de manera que saben - sin que se les haya explicarlo- cuándo, a lo largo de un film o telefilm, debe seguir un close-up, o bien, un plano general. Aunque no necesariamente sepan el nombre técnico de uno y otro.

Estos alumnos no sólo han visto " $\mathrm{La}$ Guerra de las Galaxias", han visto el documental sobre su filmación y conocen al dedillo cada uno de los mecanismos que mueven a los monstruos. También conocen los trucos ilusionistas y explican, con tranquila sabiduría, cómo el abismo no es lo que parece sino que un dibujo fotografiado por separado y sobreimpuesto a otra toma.

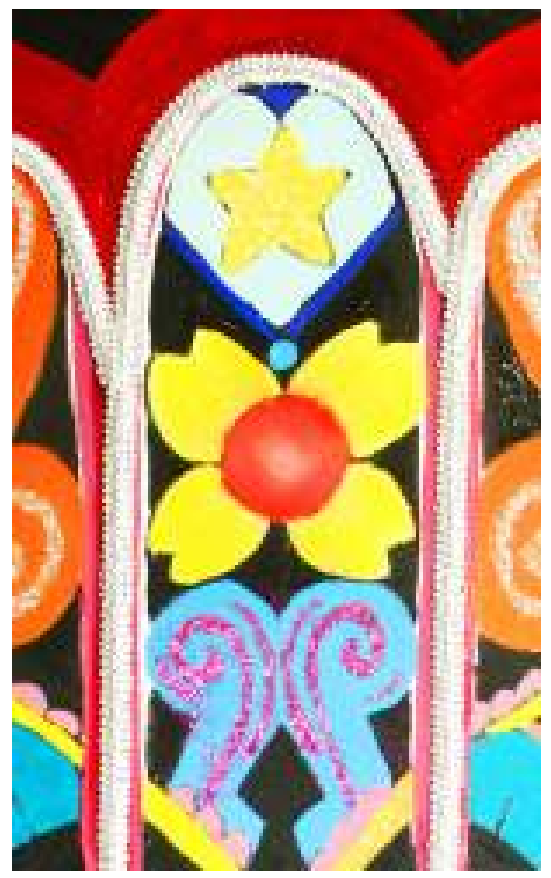

De igual forma, con la misma atención, han visto los documentales científicos sobre satélites y sondas espaciales enviados a diversos rincones del universo y con ellos, prácticamente, han sobrevolado los anillos de Saturno y han caminado sobre los cráteres de la luna.

Para la generación de los lectores, los fantasmas de luz que invadían una pantalla eran más reales que muchos de los espectadores (al menos durante la proyección) y padecían 0 gozaban junto con y gracias a ellos.

Hoy no, hoy los jóvenes saben que se trata de una película y rara vez lo ol-

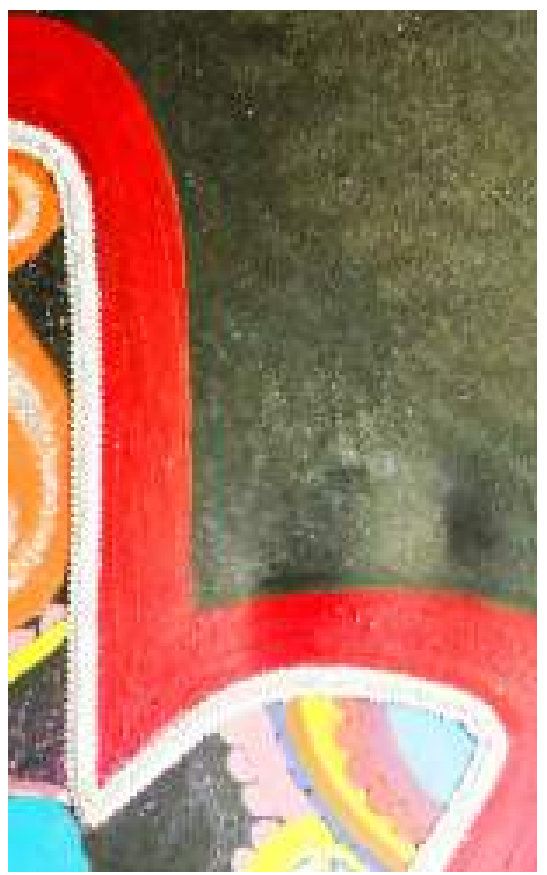


vidan. Por eso tampoco les ocasiona ningún problema sustituirla por el videocassette.

Estoy consciente de que muchos de esos argumentos rebasan la docencia. Atañen muchos más a lo psicológico, a lo psicolinguístico o a lo psicosocial y, sin embargo, todo eso influye en la dinámica del proceso de enseñanza-aprendizaje en el salón de clases. La diferencia de formación de una y otra generación está presente en nuestras aulas. A menudo, la manera de percibir el mundo no es sólo distinta sino opuesta y ni maestros, ni alumnos han sido educados para entender que el otro también puede tener la razón.

Debo confesar que a pesar de la reflexión anterior, formo parte de la legión de maestros que insiste en despertar el interés por la lectura en estos jóvenes amantes de la lectura visual. Formo parte del grupo que lucha por acabar con los programas tradicionales y buscar diseñar programas llenos de lecturas verdaderamente significativas para los jóvenes. Pero desde su punto de vista, no desde el nuestro.

Sabemos que si logramos contagiarlos con el virus de la palabra escrita, tarde o temprano llegaran a Home- ro y al Arcipestre. Nadie muerde la manzana de la verdadera lectura impunemente: está perdido para siempre; deberá leer el resto de sus días. No hay marcha atrás, sólo vuelta de hojas. ¿Cómo contagiarlos? Esa es la pregunta.

Tampoco debemos olvidar que el libro, dentro de la historia de la humanidad es muy reciente. Durante siglos, la lectura fue algo total y absolutamente elitista. Sólo unos cuantos, tenían acceso a ellos. Por eso era tan sencillo distinguir a quienes jugaban el papel de intelectuales. Ni siquiera después de la invención de la imprenta el libro se popularizó -en el sentido exacto del término.

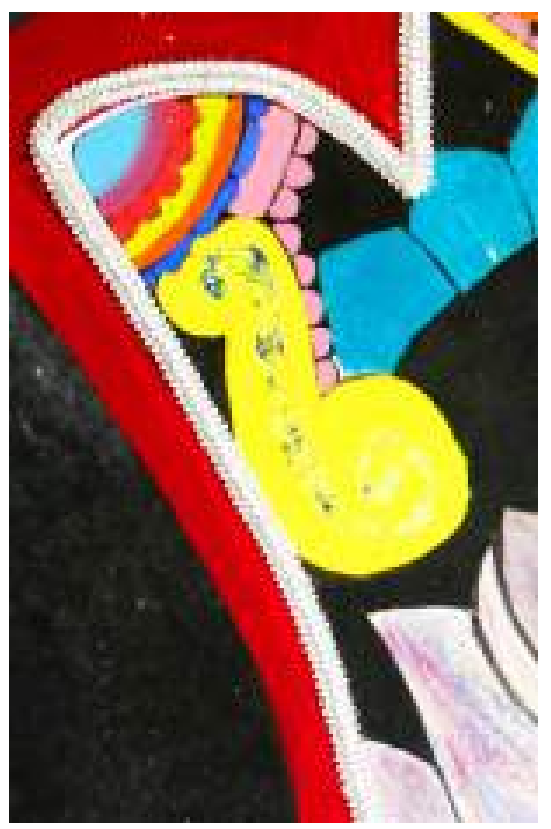

Nadie muerde la manzana de la

verdadera lectura impunemente:

está perdido para siempre; deberá leer

el resto de sus días. No hay marcha atrás, sólo vuelta de hojas
Si la lectura tiene menos de doscientos años como fuente principal de información y de educación, si muchos de los grandes artistas e inventores de otro siglo no sabían - ni necesitaban- leer, ¿no estaremos cegándonos ante las fuentes de conocimiento de una generación que no es la nuestra?

El cambio tecnológico es lo más vertiginoso en nuestros días. Y nuestra resistencia al cambio, lo más lento. Creo que como seres educados y maduros debemos obligarnos a buscar y a entender nuevas formas de lectura no verbal. Eso, si queremos conservar la capacidad para educar a las nuevas generaciones. Si no, conseguir aferrados a nuestro discurso gastado basta.

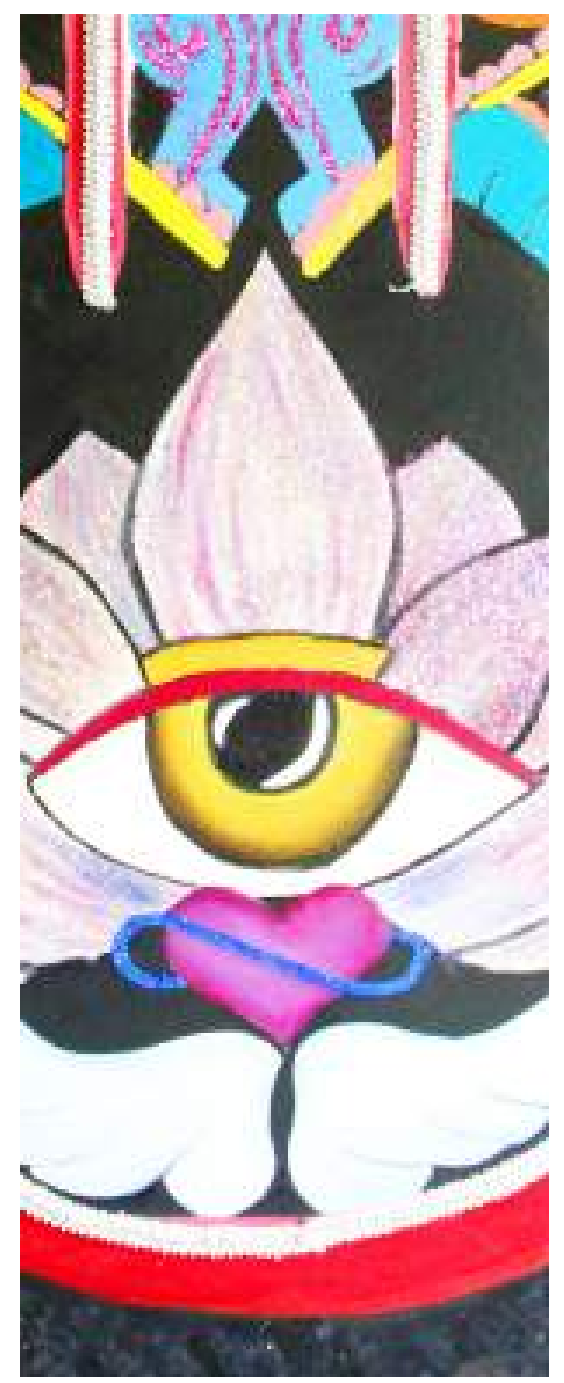

